Sharif University of Technology
Scientia Iranica
Transactions E: Industrial Engineering
IRAN I I IA

\title{
An integrated pricing and inventory model for deteriorating products in a two-stage supply chain under replacement and shortage
}

\author{
E. Teimoury* and S.M.M. Kazemi \\ Department of Industrial Engineering, Iran University of Science and Technology, Narmak Street, Tehran, Iran.
}

Received 17 April 2015; received in revised form 6 September 2015; accepted 7 December 2015

\section{KEYWORDS \\ Optimization; \\ Supply chain; \\ Inventory; \\ Pricing; \\ Deterioration; \\ Replacement; \\ Shortage.}

\begin{abstract}
In this paper, a two-stage supply chain, including a wholesaler and a retailer, is investigated, in which the retailer acts as a vendor and sells the products to the final customers. This chain only produces a single deteriorating product with constant deteriorating rate. In this chain, demand is deterministic, and lead time for replenishment and replacement of retailer's stock is considered to be zero. The objective of this study is to maximize total chain's profit by determining the optimal values of retailer's selling price $(p)$ and order cycle length $(T)$. Since due to deterioration, a part of the initial stock is deteriorated, the retailer residuals recycle the deteriorated part and replace them with healthy product as needed instead. Two scenarios with and without shortage assumptions are developed. Finally, numerical examples are presented to show the applicability of the proposed models, and sensitivity analysis on some parameter's values is conducted.

(C) 2017 Sharif University of Technology. All rights reserved.
\end{abstract}

\section{Introduction}

Nowadays, a supply chain coordination has great importance in competitive business environments. Close cooperation between the members of the multi-stage supply chain results in a noticeable increase in total profit as well as faster response to the client's demand. Also, determining the optimal inventory control policy and selling price for different products is one of the main issues of industrial and scientific studies, especially when the product is perishable. So, in this paper, we concentrate on simultaneous pricing and inventory decisions in a two-stage supply chain for deteriorating products with replacement and shortage assumptions. In this section, we will review some research pieces about replacement, pricing, and inventory decision for deteriorating product.

*. Corresponding author. Tel: +982173225000

E-mail addresses: Teimoury@iust.ac.ir (E. Teimoury);

sm_kazemi@iust.ac.ir (S.M.M.Kazemi)
Since in the absence of product price is usually the main factor for customer's buying decision, joint determination of pricing and inventory decisions is an important problem. Yu et al. [1] determined the joint optimal price-inventory decisions in a fuzzy pricedependent newsvendor framework. Huang et al. [2] modeled the coordination of suppliers and components selection, pricing and replenishment decisions in a three-level supply chain as a dynamic non-cooperative game model. Ghoreishi et al. [3] dealt with an economic production quantity inventory model for noninstantaneous deteriorating items under inflationary conditions, permissible delay in payments, customer returns, and price- and time-dependent demand. Zhu [4] formulated the combined pricing and inventory control problem in a random demand condition and finite planning horizon with return and expediting. You et al. [5] studied a seasonal inventory model with trial periods during which customers can return their purchases without paying any penalty and developed a mathematical model. Lee et al. [6] formulated a novel 
fuzzy multi-level multi-objective production planning model for a supply chain under a fuzzy environment. $\mathrm{Su}$ and Geunes [7] examined the degree to which the bullwhip effect results from price fluctuation in a two-stage supply chain with deterministic demand. Mutlu and Çetinkaya [8] concentrated on a carrierretailer channel and compared the profitability of the centralized and decentralized channels under a pricedependent demand. Hong and Lee [9] studied a single-product inventory system and applied shipment consolidation (time-based policy) in order to maximize total profit and determine optimum values of selling price, replenishment quantity and dispatch cycle length simultaneously. Abad [10] formulated a model to determine selling price and order size for perishable products with partial backordering. Adida and Perakis [11] presented a model for dynamic pricing and inventory problem for a make-to-stock manufacturing system. Dong et al. [12] studied the problem of product line selection and pricing. Gümüs and Güneri [13] reviewed the literature, addressing multi-echelon inventory management in supply chains from 1996 to 2005.

On the other hand, since in today's market, the number of deteriorating products shows a real increasing trend, so many researchers have concentrated on inventory control of these products. In this way, Chew et al. [14] studied an inventory system and determined the inventory allocation and the price for a perishable product with a predetermined lifetime. Taleizadeh and Nematollahi [15] developed an inventory control model that investigates the effects of time value of money and inflation on optimal ordering policy of deteriorating products. Lee and Chung [16] used system dynamics thinking to propose a new order system for deteriorating products and prepare a systematical simulation. Maity and Maiti [17] presented an optimum production and advertising policy for a multiproduct system with inflation and time discounting under different constraints. Yu et al. [18] studied an inventory problem for a VMI system, where both the raw material and finished products are perishable. Mahata [19] formulated an EPQ-based inventory model for deteriorating products that investigates the optimal retailer's replenishment decisions under trade credit policy. Also, as we know, the pricing models of deteriorating items due to similarity to real business environments, has a special place in scientific research. For example, Chung et al. [20] investigated the effects of stock- and warranty- dependent demands on an integrated two-stage production-inventory deteriorating model. Yang [21] developed an optimal pricing and ordering policy for a deteriorating item using a quantity discount pricing strategy. Dye et al. [22] found the optimal inventory and pricing strategies for a single-product economic order quantity that maximize total profit over an infinite horizon. Tsao and
Sheen [23] studied the problem of dynamic pricing, promotion, and replenishment for a deteriorating item with supplier's trade credit and retailer's promotional efforts. Huang [24] developed an integrated inventory model in a two-stage supply chain to determine the optimal policy under order processing cost reduction and permissible delay in payments. Maihami and Nakhai [25] considered a joint pricing and inventory control model for non-instantaneously deteriorating items with permissible delay in payments; shortage is allowed and partially backlogged in their model.

Furthermore, in case of deteriorating products, using a kind of replacement policies in relation with deteriorated items can be useful. For example, Gomez et al. [26] investigated the simultaneous production planning and quality problem for an unreliable single machine manufacturing system responding to a singleproduct type demand. Nguyen et al. [27] studied the impact of spare parts inventory on equipment maintenance and replacement decisions under technological change via a Markov process formulation. Jain and Gupta [28] studied an optimal replacement policy for a repairable system with multiple vacations and imperfect fault coverage. Berthaut et al. [29] considered a joint preventive maintenance and production/inventory control policy of an unreliable single machine, mono-product manufacturing cell. Guchhait et al. [30] developed Economic Production Quality (EPQ) models for breakable items. Cheng and $\mathrm{Li}$ [31] studied an optimal replacement policy for a degenerative system with two types of failure states. Chang [32] considered an optimal replacement policy for a degenerative system with two types of failure states. Sivazlian and Danusaputro [33] discussed economic inventory and replacement management of a system in which components are subject to failure. Teimoury and Fathi [34] studied Order Penetration Point (OPP) strategic decision-making, which is the boundary between Make-To-Order (MTO) and Make-To-Stock (MTS) policies, considering twoechelon supply chain. Teimoury et al. [35] employed some innovative methodologies of multi-agent systems development to create an automation of the supply chain performance measurement based on multi-agent system. Teimoury and Fathi [36] studied An integrated operations-marketing perspective for making decisions about order penetration point in multi-product supply chain using a queuing approach. Teimoury and Haddad [37] studied a supply chain production scheduling with deterioration and release date. Taleizadeh et al. [38] developed a VMI model for a two-level supply chain in which both the raw material and the finished product have different deterioration rates. The market demand for the finished product is deterministic and price-sensitive. The Stackelberg approach is considered between the chain partners, where the vendor is the 
leader, and the retailers are the followers. Rahdar and Nookabadi [39] considered a supply chain including a manufacturer and several buyers and assumed that the inventory items deteriorate over time and its inventory level decreases. In order to determine the order policies, coordination over the supply chain is achieved by scheduling the buyers' delivery days and their coordination with the manufacturer's production cycle. Sarkar [40] considered that a productioninventory model is developed for a deteriorating item in a two-echelon Supply Chain Management (SCM). An algebraic approach is applied to find the minimum cost related to this entire SCM. Three types of the continuous probabilistic deterioration function are considered to find the associated cost.

As a result, although many outstanding research pieces about pricing and inventory control model for deteriorating product have been separately developed up to now, none of them has considered replacement, inventory, and pricing policies in a two-stage supply chain together. As for more clarification, the significance of our research comes up whenever one is studying the profitability of food industries by focusing on a special dairy product factory in which a large number of products are deteriorating every minute and the inventory of healthy products are becoming smaller; since there is a direct relationship between stock's healthy inventory and profit, a smaller profit will be obtained. Now, here a replacement policy can help us to replace the deteriorated items with healthy ones, and in this way to compensate for a part of our loss. The above-mentioned hints are the noticeable gaps in this context that motivate us for this study. In this research, we develop an integrated pricing-inventory system for a deteriorating item in a two-stage supply chain, in which a kind of replacement policy is used.

The rest of the paper is organized as follows. The problem is defined in Section 2. In Section 3 , we develop a mathematical model for products with constant deteriorating rate and price-dependent demand, and then, we determine the optimum values of product price and order cycle length simultaneously, and a solution method is presented. In Section 4, we present our first model by adding shortage assumption. Numerical examples are provided in Section 5. Finally, paper is concluded in Section 6.

\section{Problem definition}

Consider a two-stage supply chain consisting of a wholesaler and a retailer, that is, a single item deteriorating system with constant deteriorating rate. In this chain, the wholesaler buys the products from the upper level, the manufacturer (that is not considered in this study), and sells them to the retailer. Then, the retailer sells the products to the final customers. The main purpose of this paper is to study the inventory system of this chain and extend models to determine the optimum values of retailer's selling price $(P)$ and order cycle length $(T)$ simultaneously in order to maximize total chain's profit. In this paper, the retailer at the beginning of the order cycle purchases (orders) as cycle's demand, but since the products are deteriorating, a part of the initial stock will deteriorate during the order cycle. So, in order to respond to the customer's demand, the retailer replaces deteriorated quantities with healthy products. In other words, retailer recycles (residuals) the deteriorated products, and then replaces the deteriorated products with the healthy products. Replacement is instantaneous and repurchasing cost is considered as equal as the initial purchasing price. Also, lead time for stock's replenishment is considered to be zero. Moreover, in order to determine the retailer's optimal selling price, it is assumed that customer's demand is deterministic and a linear function of product price $D(p)=(a-b p)$, where $a$ and $b$ are positive and constant values $a, b>0$. Two scenarios are developed with and without shortage assumptions. In the first scenario, shortage is not permitted and all demands must be satisfied; in the second scenario, shortage is permitted and will be completely backlogged.

In this section, we present mathematical models for integrated pricing and inventory decisions for deteriorating products in a two-stage supply chain with replacement and shortage assumption. In order to model the problem, the following notations are used.

\section{Parameters}

$I(t) \quad$ The inventory level at time $t$ in interval $[0, T]$

$\beta(t) \quad$ The inventory level at time $t$ in interval $\left[T, T^{\prime}\right]$

$\theta \quad$ The constant deteriorating rate

$D(p) \quad$ The price-sensitive demand

$F_{D} \quad$ The fixed cost of a dispatch

$C_{D} \quad$ The dispatching cost per unit product

$F_{p} \quad$ The fixed cost of a ordering (purchasing)

$C_{p} \quad$ The ordering (purchasing) cost per unit product

$C_{H} \quad$ The recycling cost (salvage value) of per unit deteriorated product

$Q_{p} \quad$ The amount of deteriorated product

$h \quad$ The holding cost per unit product per unit of time

$S \quad$ The maximum backlogged shortage

$\delta \quad$ The backlogged shortage cost per unit product

$T^{\prime} \quad$ The ordering time 
$C^{\prime} \quad$ The wholesaler's purchasing price

\section{Decision variables}

$P \quad$ The retailer's selling price

$T \quad$ The ordering (purchasing) cycle length

\section{Mathematical modelling}

\subsection{The first scenario: without shortage}

In this scenario, shortage is not permitted and all demands must be satisfied. In this part, we present a mathematical model for integrated pricing and inventory decisions for deteriorating products in a two-stage supply chain in which shortage is not permitted. First, we model the retailer and wholesaler's profit functions separately, and then form an integrated profit function.

\subsubsection{Retailer's profit function}

According to Figure 1, differential equations, shown in Eq. (1), present the changes of inventory level of the retailer during the ordering cycle, interval $[0, T]$ :

$$
\frac{d I(t)}{d t}=-\theta I(t)-D(p) ; \quad t \in[0, T] .
$$

Using the boundary condition $I(T)=0$, we have:

$$
I(t)=\frac{D(p)}{\theta}\left(e^{\theta(T-t)}-1\right) .
$$

Moreover, the maximum inventory level during the interval $[0, T]$ will be:

$$
I(0)=\frac{D(p)}{\theta}\left(e^{\theta T}-1\right) .
$$

In order to determine the optimal value of decision variables, firstly, we need to model the profit function, and we know that profit is the difference between income and cost. In this study, $T$ is considered as ordering cycle and demand during this cycle is $D(p)$. So, income will be:

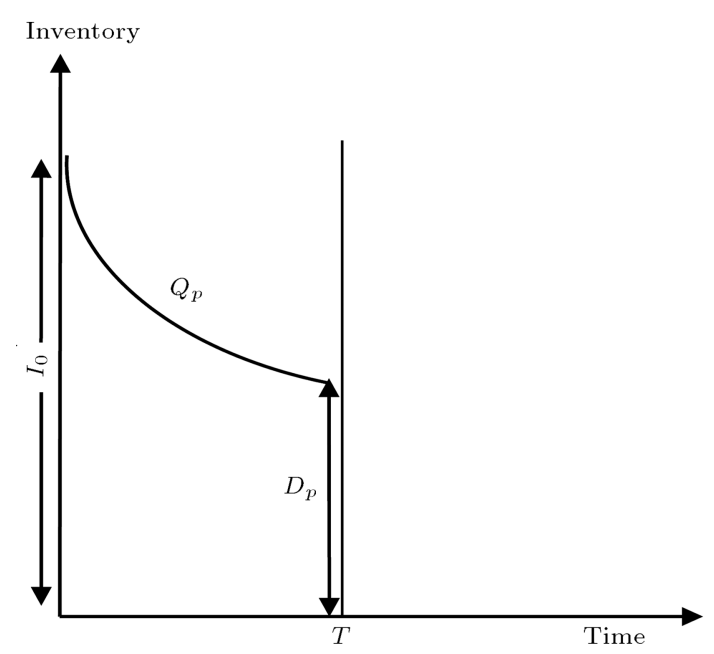

Figure 1. Inventory diagram without shortage.

$$
D(p) T p=(a-b p) T p .
$$

Moreover, the cost function of retailer includes purchasing, dispatch, holding, and replacement costs which are calculated as below.

\section{Purchasing cost:}

In this model, the purchasing quantity is equal to the cycle's demand $D(p) T$. By having $F_{p}$ as the fixed cost of purchasing and $C_{p}$ as purchasing cost of per unit product, for purchasing cost, we have:

$$
F_{p}+C_{p} D(p) T
$$

\section{Dispatch cost:}

Dispatch quantity is equal to $D(p) T$. So, by having $F_{D}$ as the fixed cost of dispatching and $C_{D}$ as dispatching cost of per unit product, the dispatch cost during the ordering cycle will be:

$$
F_{D}+C_{D} D(p) T
$$

\section{Holding cost:}

According to Eq. (2), we know that the inventory level at time $t$ is $I(t)=\frac{D(p)}{\theta}\left(-1+e^{\theta(T-t)}\right)$. Utilizing a truncated Taylor series expansion for the exponential term, $e^{\theta T}=1+\theta T+\frac{\theta^{2} T^{2}}{2}$, the inventory holding cost in each ordering cycle is:

$$
\begin{aligned}
h \int_{0}^{T} I(t) d t & =h \int_{0}^{T}\left(\frac{D(p)}{\theta}\left(-1+e^{\theta(T-t)}\right)\right) d t \\
& =\frac{h D(p) T^{3}}{2}=\frac{h(a-b p) T^{2}}{2} .
\end{aligned}
$$

\section{Replacement cost:}

Replacement cost is defined as the difference between the purchasing cost of per unit deteriorated product and its salvage value (recycling cost). Now, the deteriorated quantity is equal to:

$$
Q_{p}=I(0)-I(T)-D(p) T
$$

where $I(0)=\frac{D(p)}{\theta}\left(e^{\theta T}-1\right), I(T)=0$ and demand during the ordering cost is $D(p) T$. So, deteriorated quantity is:

$$
\begin{aligned}
Q_{p} & =I(0)-I(T)-D(p) T \\
& =\frac{D(p)}{\theta}\left(e^{\theta T}-1\right)-D(p) T .
\end{aligned}
$$

Utilizing a truncated Taylor series expansion for the exponential term, $e^{\theta T}=1+\theta T+\frac{\theta^{2} T^{2}}{2}$, replacement cost in each ordering cycle is: 


$$
\begin{aligned}
C_{p}\left(Q_{p}\right) & -C_{H}\left(Q_{p}\right)=\left(C_{P}-C_{H}\right) Q_{p} \\
& =\left(C_{p}-C_{H}\right)\left(\frac{D(p) \theta T^{2}}{2}\right),
\end{aligned}
$$

where $C_{p}$ is the purchasing cost of per unit deteriorated product, which is considered equal to the initial purchasing price. And, $C_{H}$ is recycling cost (residual value), which means that if the deteriorated product is repairable, then $C_{H}$ is the recycling cost; otherwise, $C_{H}$ is the residual value. Using Eqs. (4)-(7) and (10), the retailer's total profit function is:

$$
\begin{aligned}
T P_{r}(p, T)= & D(p) p T-\left\{F_{P}+C_{P} D(p) T\right. \\
& +\frac{h D(p) T^{2}}{2}+F_{D}+C_{D} D(p) T \\
& \left.+\left(C_{P}-C_{H}\right)\left(\frac{D(p) \theta T^{2}}{2}\right)\right\} .
\end{aligned}
$$

\subsubsection{Wholesaler's profit function}

Wholesaler's profit function is also the difference between its income and cost. Here, wholesaler's cost function only includes purchasing cost, and income is the obtained from selling the products to the retailer:

$$
\begin{aligned}
T P_{w}(p, T)= & C_{p} I(0)-C^{\prime} I(0)=\left(C_{p}-C^{\prime}\right) I(0) \\
= & \left(C_{p}-C^{\prime}\right) D(p) T \\
& +\frac{\left(C_{p}-C^{\prime}\right) D(p) \theta T^{2}}{2}
\end{aligned}
$$

where $I(0)$ is the product quantity that wholesaler sells to the retailer, $C_{p}$ is the selling price from wholesaler to retailer, and $C^{\prime}$ is the wholesaler's purchasing cost (the wholesaler buys the products with purchasing cost $C^{\prime}$ from manufacturer; manufacturer is not considered in this study).

Using Eqs. (11) and (12), the integrated total profit function is the sum of total profit functions of retailer and wholesaler, and it is obtained as below:

$$
\begin{aligned}
T P(p, T)= & T P_{w}(p, T)+T P_{r}(p, T) \\
= & \left(C_{p}-C^{\prime}\right) D(p) T+\frac{\left(C_{p}-C^{\prime}\right) D(p) \theta T^{2}}{2} \\
& +D(p) p T-\left\{F_{P}+C_{P} D(p) T\right. \\
& +\frac{h D(p) T^{2}}{2}+F_{D}+C_{D} D(p) T \\
& \left.+\left(C_{P}-C_{H}\right)\left(\frac{D(p) \theta T^{2}}{2}\right)\right\} .
\end{aligned}
$$

\subsection{Solution method}

Theorem1. $T P(p, T)$ is strictly concave if and only if:

$$
C_{D}<3 p-C^{\prime}-\frac{a}{b}+\frac{T}{2}\left(\theta\left(C^{\prime}-C_{H}\right)+h\right)\left(\frac{a}{b p}-3\right) .
$$

Proof. $T P(p, T)$ is strictly concave if and only if:

$$
X . H . X^{T}=[p T] \times H \times[p T]^{T}<0
$$

where:

$$
\begin{gathered}
H=\left[\begin{array}{ll}
\frac{\partial^{2} T P}{\partial p^{2}} & \frac{\partial^{2} T P}{\partial p \partial T} \\
\frac{\partial^{2} T P}{\partial T \partial p} & \frac{\partial^{2} T P}{\partial T^{2}}
\end{array}\right] \\
=\left[\begin{array}{c}
-2 b T \\
b\left[\left(C^{\prime}+C_{D}\right)+T\left(\theta\left(C^{\prime}-C_{H}+h\right)\right]+(a-2 b p)\right. \\
\left.b\left[\left(C^{\prime}+C_{D}\right)+T\left(\theta\left(C^{\prime}-C_{H}\right)+h\right)\right]+(a-2 b p)\right] \\
-D(p)\left(\theta\left(C^{\prime}-C_{H}\right)+h\right)
\end{array}\right.
\end{gathered}
$$

So, we have:

$$
\begin{aligned}
X \times & H \times X^{T}=-6 b T p^{2}+3 b p T^{2} \theta C^{\prime}+3 b p T^{2} h \\
& -3 b p \theta C_{H} T^{2}+2 b p T C^{\prime}+2 a p T+2 b p T C_{D} \\
& -a \theta C^{\prime} T^{2}-a h T^{2}+a \theta C_{H} t^{2} .
\end{aligned}
$$

We should show that:

$$
\begin{aligned}
X \times H & \times X^{T}=\left\{-6 b T p^{2}+3 b p T^{2} \theta C^{\prime}+3 b p T^{2} h\right. \\
& -3 b p \theta C_{H} T^{2}+2 b p T C^{\prime}+2 a p T+2 b p T C_{D} \\
& \left.-a \theta C^{\prime} T^{2}-a h T^{2}+a \theta C_{H} T^{2}\right\}<0 .
\end{aligned}
$$

So, the profit function $T P(p, T)$ is strictly concave if and only if:

$$
C_{D}<3 p-C^{\prime}-\frac{a}{b}+\frac{T}{2}\left(\theta\left(C^{\prime}-C_{H}\right)+h\right)\left(\frac{a}{b p}-3\right) .
$$

The proof is completed $\square$.

Now, taking the first derivative of Eq. (13) with respect to $p$, we have:

$$
\begin{aligned}
\frac{\partial T P(p, T)}{\partial p}= & a T-2 b p T+b T C^{\prime}+b t C_{D}+\frac{b C^{\prime} \theta T^{2}}{2} \\
& -\frac{b C_{H} \theta T^{2}}{2}+\frac{b h T^{2}}{2}
\end{aligned}
$$

On the other hand, the first derivatives of Eq. (13) with respect to $T$ yield:

$$
\begin{aligned}
\frac{\partial T P(p, T)}{\partial T}= & \left(-C^{\prime}-C^{\prime} \theta T-h T-C_{D}\right. \\
& \left.+C_{H} \theta T\right) D(p)+D(p) p .
\end{aligned}
$$

By setting Eq. (17) equal to zero, we have: 


$$
p^{*}=\frac{a}{2 b}+\frac{C^{\prime}}{2}+\frac{C_{D}}{2}+\frac{C^{\prime} \theta T}{4}-\frac{C_{H} \theta T}{4}+\frac{h T}{4}
$$

By substituting Eq. (19) into Eq. (18) and setting it equal to zero, Eq. (18) changes to Eq. (20) as follows:

$$
A T^{2}+B T+C=0
$$

where:

$$
\begin{aligned}
& A=\frac{3 b}{16}\left(\theta\left(C^{\prime}-C_{H}\right)+h\right)^{2}, \\
& B=\frac{1}{2}\left(b\left(C^{\prime}-C_{D}\right)-a\right)\left(\theta\left(C^{\prime}-C_{H}\right)+h\right), \\
& C=\frac{1}{4}\left(\sqrt{b}\left(C^{\prime}+C_{D}\right)-\frac{a}{\sqrt{b}}\right)^{2} .
\end{aligned}
$$

By solving the above equation, $T^{*}$ is obtained as follows:

$$
\begin{aligned}
T^{*} & =\frac{2\left[\frac{a}{b}-\left(C^{\prime}+C_{D}\right)\right]}{\left[\theta\left(C^{\prime}-C_{H}\right)+h\right]} \text { or } \\
T^{*} & =2 \frac{\left[\frac{a}{b}-\left(C^{\prime}+C_{D}\right)\right]}{3\left[\theta\left(C^{\prime}-C_{H}\right)+h\right]} .
\end{aligned}
$$

\section{The second scenario: with shortage}

\subsection{Mathematical model Retailer's profit function:}

According to Figure 2, differential equations, shown in Eq. (1), present the changes of inventory level of the retailer during the first interval.

In second interval, shortage will happen and will be completely backlogged. So, differential Eq. (25) presents the changes of inventory level during the second interval:

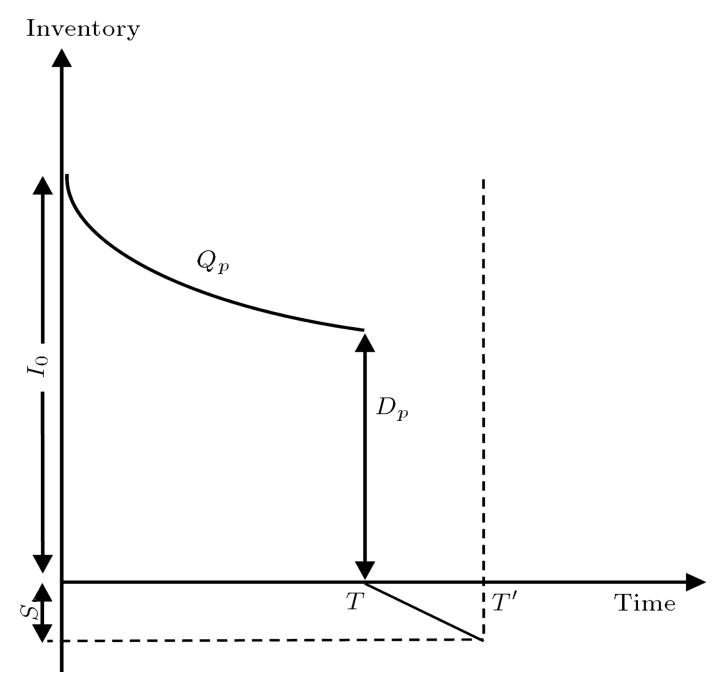

Figure 2. Inventory diagram under shortage.

$$
\frac{d \beta(t)}{d t}=D(p) ; \quad t \in\left[T, T^{\prime}\right]
$$

Using the boundary condition, $\beta(T)=0$, for interval $\left[T, T^{\prime}\right]$, we have:

$$
\beta(t)=D(p)(t-T) .
$$

The maximum level of backlogged shortage $(S)$ will be:

$$
S=\beta\left(T^{\prime}\right)=D(p)\left(T^{\prime}-T\right) .
$$

In the following model, as we know, income will be the sum of which obtained from selling of products in the first interval and income which obtained from selling of backlogged shortages in the second interval. According to Eq. (4), income in the first interval is $D(p) T p$; income in the second interval is:

$$
p \times S=p \times\left(D(p)\left(T^{\prime}-T\right)\right)=p D(p) T^{\prime}-p D(p) T .
$$

So, the total income of replenishment cycle will be:

$$
p D(p) T+p D(p) T^{\prime}-p D(p) T=p D(p) T^{\prime} .
$$

Moreover, the cost function of retailer includes purchasing, dispatch, holding, replacement, and shortage costs which are calculated as below.

\section{Purchasing cost:}

In this model, we purchase according (as) to the demand of the first interval $D(p) T$ and the maximum level of backlogged shortage $S$. So, for purchasing cost, we have:

$$
\begin{aligned}
F_{P} & +C_{P}(D(p) T+S)=F_{P}+C_{P}(D(p) T-D(p) T \\
& \left.+D(p) T^{\prime}\right)=F_{P}+C_{P} D(p) T^{\prime}
\end{aligned}
$$

\section{Dispatch cost:}

As mentioned, the dispatch cost in the first interval is $F_{D}+C_{D} D(p) T$; in second interval, in order to reduce customer's waiting time, it is assumed that all the backlogged shortages will be dispatched at once. So, the total dispatch costs in each ordering cycle is:

$$
\begin{gathered}
F_{D}+C_{D} D(p) T+F_{D}+C_{D} S=F_{D}+C_{D} D(p) T+F_{D} \\
+C_{D}\left\{-D(p) T+D(p) T^{\prime}\right\}=2 F_{D}+C_{D} D(p) T^{\prime} .(31)
\end{gathered}
$$

\section{Holding cost:}

Since inventory exists in the first interval, the holding cost is defined only in the first interval. And, according to Eq. (7), it is $\frac{h D(p) T^{2}}{2}$.

\section{Backlogged shortage cost:}

Backlogged shortage cost is only defined in the second interval and is calculated as below: 


$$
\delta \times S=\delta\left(D(p)\left(T^{\prime}-T\right)\right)=-\delta(D p) T+\delta D(p) T^{\prime}
$$

\section{Replacement cost:}

Accordingly, Eq. (10) is equal to $\left(C_{p}-C_{H}\right)\left(\frac{D(p) \theta T^{2}}{2}\right)$.

Using Eqs. (7), (10) and (29) to (32), the retailer's total profit function is:

$$
\begin{aligned}
T P_{r}(p, T)= & D(p) p T^{\prime}-\left\{F_{P}+C_{P} D(p) T^{\prime}\right. \\
& +\frac{h D(p) T^{2}}{2}+2 F_{D}+C_{D} D(p) T^{\prime} \\
& +\left(C_{P}-C_{H}\right)\left(\frac{D(p) \theta T^{2}}{2}\right)+\delta D(p) T^{\prime} \\
& -\delta D(p) T\} .
\end{aligned}
$$

\section{Wholesaler's profit function:}

As mentioned before, wholesaler's profit function is:

$$
\begin{aligned}
T P_{w}(p, T) & =C_{p}(I(0)+S)-C^{\prime}(I(0)+S) \\
& =\left(C_{p}-C^{\prime}\right)(I(0)+S)=\left(C_{p}-C^{\prime}\right) D(p) T^{\prime} \\
& +\frac{\left(C_{p}-C^{\prime}\right) D(p) \theta T^{2}}{2}
\end{aligned}
$$

in which $(I(0)+S)$ is the product quantity that wholesaler sells to the retailer.

Using Eqs. (33) and (34), the integrated total profit function is the sum of retailer and wholesaler's total profit functions and is obtained as below:

$$
\begin{aligned}
T P(p, T) & =T P_{w}(p, T)+T P_{r}(p, T) \\
& =\left(C_{p}-C^{\prime}\right) D(p) T^{\prime}+\frac{\left(C_{p}-C^{\prime}\right) D(p) \theta T^{2}}{2} \\
& +D(p) p T^{\prime}-\left\{F_{P}+C_{P} D(p) T^{\prime}+\frac{h D(p) T^{2}}{2}\right. \\
& +2 F_{D}+C_{D} D(p) T^{\prime}+\left(C_{P}-C_{H}\right) \\
& \left.\left(\frac{D(p) \theta T^{2}}{2}\right)+\delta D(p) T^{\prime}-\delta D(p) T\right\}
\end{aligned}
$$

\subsection{Solution method}

Theorem 2. $T P(p, T)$ is strictly concave if and only if $a>3 b p$.

Proof. $T P(p, T)$ is strictly concave if and only if:

$$
X . H . X^{T}=[p T] \times H \times[p T]^{T}<0
$$

where:

$$
\begin{aligned}
H= & {\left[\begin{array}{ll}
\frac{\partial^{2} T P}{\partial p^{2}} & \frac{\partial^{2} T P}{\partial p \partial T} \\
\frac{\partial^{2} T P}{\partial T \partial p} & \frac{\partial^{2} T P}{\partial T^{2}}
\end{array}\right] } \\
= & {\left[\begin{array}{c}
-2 b T^{\prime} \\
-b T\left(\theta\left(C_{H}-C^{\prime}\right)-h\right)-b \delta \\
-b T\left(\theta\left(C_{H}-C^{\prime}\right)-h\right)-b \delta \\
D(p)\left(\theta\left(C_{H}-C^{\prime}\right)-h\right)
\end{array}\right] . }
\end{aligned}
$$

So, we have:

$$
\begin{aligned}
X \times H \times X^{T}= & -T^{2}\left(\theta\left(C^{\prime}-C_{H}\right)+h\right)(a-3 b p) \\
& -2 b p\left(T^{\prime} p+T \delta\right)
\end{aligned}
$$

We should show that:

$$
\begin{aligned}
X \times H \times X^{T}= & -T^{2}\left(\theta\left(C^{\prime}-C_{H}\right)+h\right)(a-3 b p) \\
& -2 b p\left(T^{\prime} p+T \delta\right)<0 .
\end{aligned}
$$

By having this assumption that $C^{\prime} \geq C_{H}$, the profit function, $\operatorname{TP}(p, T)$, is strictly concave if and only if $a>3 b p$. The proof is completed $\square$.

Considering Eq. (35) with respect to $p$, we have:

$$
\begin{aligned}
\frac{\partial T P(p, T)}{\partial p}= & a T^{\prime}-2 b p T^{\prime}+b T^{\prime} C^{\prime}+b T^{\prime} C_{D} \\
& +\frac{b C^{\prime} \theta T^{2}}{2}-\frac{b C_{H} \theta T^{2}}{2}+b \delta T^{\prime} \\
& -b \delta T+\frac{b h T^{2}}{2} .
\end{aligned}
$$

On the other hand, the first derivatives of Eq. (35) with respect to $T$ yield:

$$
\frac{\partial T P(p, T)}{\partial T}=\left(-C^{\prime} \theta T-h T+C_{H} \theta T+\delta\right) D(p) .
$$

By setting Eq. (39) equal to zero, we have:

$$
p^{*}=\frac{a}{2 b}+\frac{C^{\prime}}{2}+\frac{C_{D}}{2}+\frac{\delta}{2}-\frac{\delta T}{2 T^{\prime}}+\frac{C^{\prime} \theta T^{2}}{4 T^{\prime}}+\frac{h T^{2}}{4 T^{\prime}} .
$$

By substituting Eq. (41) into Eq. (40) and setting it equal to zero, Eq. (40) changes to Eq. (42) as follows:

$$
A T^{3}+B T^{2}+C T+D=0
$$

where:

$$
\begin{aligned}
& A=\frac{b}{4 T^{\prime}}\left(\theta\left(C_{H}-C^{\prime}\right)-h\right)^{2}, \\
& B=\frac{3 \delta b}{4 T^{\prime}}\left(\theta\left(C_{H}-C^{\prime}\right)-h\right) \\
& C=\frac{1}{2}\left(\theta\left(C_{H}-C^{\prime}\right)-h\right)\left(a-b\left(C^{\prime}+C_{D}+\delta\right)\right)+\frac{b \delta^{2}}{2 T^{\prime}}, \\
& D=\frac{\delta}{2}\left(a-b\left(C^{\prime}+C_{D}+\delta\right)\right) .
\end{aligned}
$$


Finally, the optimal values of period length should be determined by solving Eq. (42).

The following solution method mentioned in Figure 3 has been presented to simplify the solution procedure for both of the proposed models as follows:

- Step 1. Computing the coefficients of polynomials shown in Eqs. (20) and (42);

- Step 2. Calculate all positive real roots of Eqs. (20) and (42) using MATLAB software. Then, check the feasibility. If the results are feasible, then go to Step 3 , terminate the solution process;

- Step 3. Determine $p$ for all feasible values of $(T)$ resulted from Step 2;

- Step 4. For all combinations of $(p, T)$, compute the total profit function and choose the higher one. Also, check the concavity condition. If the results show the concavity, then the results are the optimal values and terminate the procedure, or else go to Step 5;

- Step 5. Using a nonlinear solver toolbox solves the problem.

\section{Numerical examples}

\subsection{The first example}

For the first model, consider the parameters values as $F_{p}=40, F_{D}=40, h=14, C_{H}=10, \theta=0.04$, $C^{\prime}=20, b=0.3, a=10, C_{D}=3, C_{p}=30$, and $C_{R}=40$. According to the above-mentioned solution procedure, the highest profit obtains $T P=$ 78.2973 which corresponds to the optimum value of $p^{*}=29.8889$ as retailer's selling price and optimum value of $T^{*}=0.4784$ as order cycle length.

\subsection{The second example}

For the second model, consider the parameters values as $F_{p}=40, F_{D}=40, h=14, C_{H}=10, \theta=0.04, C^{\prime}=$

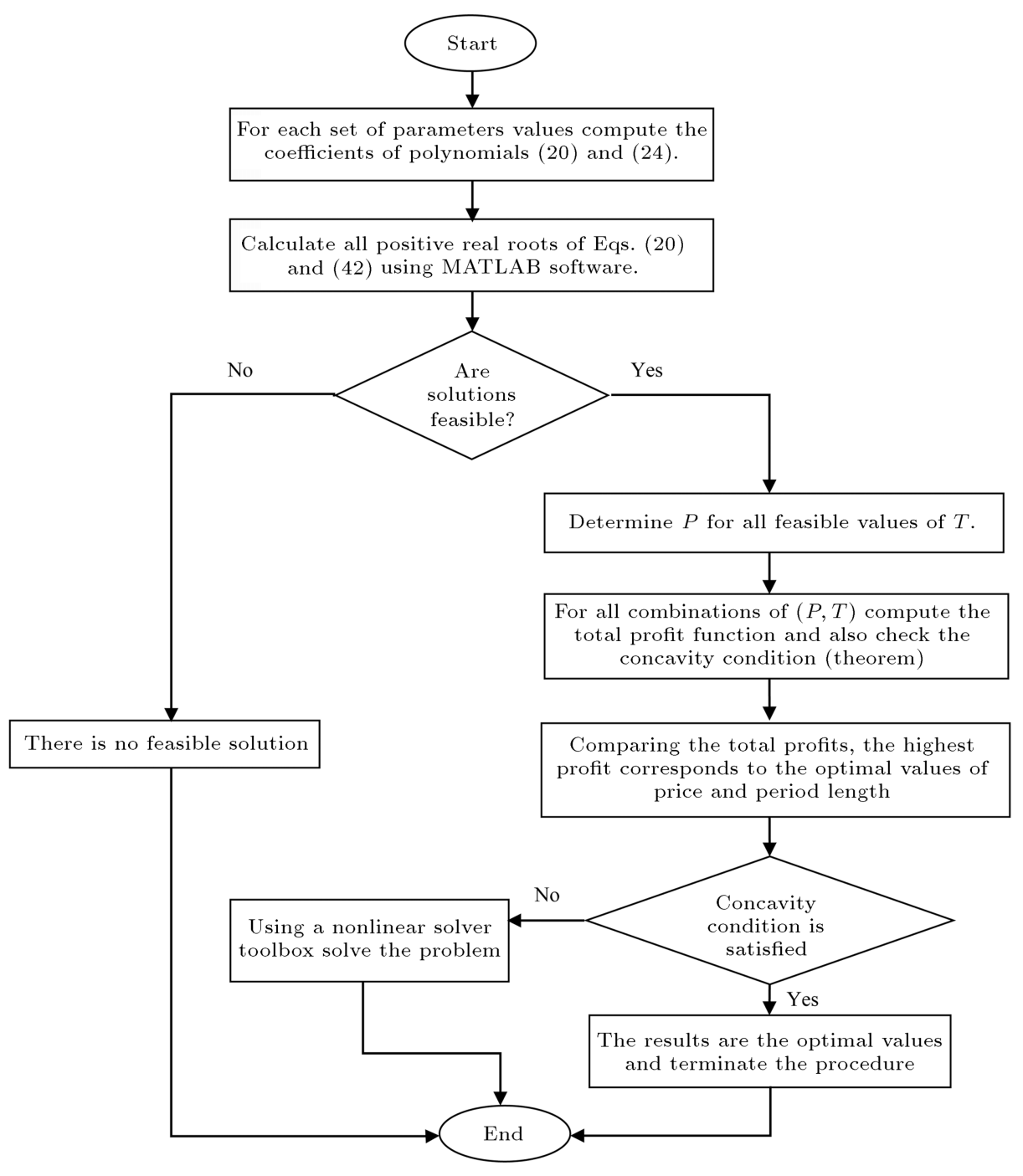

Figure 3. Flowchart of solution method. 
Table 1. Effects of parameter changes on optimal values of the first scenario.

\begin{tabular}{|c|c|c|c|c|}
\hline \multicolumn{5}{|c|}{ Changes in parameter's values } \\
\hline$\%$ & Changes in parameter & $T$ & $p$ & $T P$ \\
\hline \multirow{4}{*}{$h$} & -0.5 & +94.58 & -0.0003 & -2.057 \\
\hline & -0.25 & +32.10 & 0 & -0.698 \\
\hline & +0.25 & -19.54 & +0.0006 & +0.425 \\
\hline & +0.5 & -32.71 & -0.0003 & +0.711 \\
\hline \multirow{4}{*}{$\theta$} & -0.5 & +1.400 & -0.0003 & -0.03 \\
\hline & -0.25 & +0.689 & -0.0006 & -0.015 \\
\hline & +0.25 & -0.689 & 0 & 9.583 \\
\hline & +0.5 & -1.379 & -0.006 & 0.0297 \\
\hline \multirow{4}{*}{$C_{H}$} & -0.5 & -1.379 & -0.0006 & +0.029 \\
\hline & -0.25 & -0.689 & 0 & +0.014 \\
\hline & +0.25 & +0.689 & -0.0006 & -0.015 \\
\hline & +0.5 & +1.400 & -0.0003 & -0.030 \\
\hline \multirow{4}{*}{$C^{\prime}$} & -0.5 & +102.4038 & -11.151 & -14.875 \\
\hline & -0.25 & +50.480 & -5.575 & -5.030 \\
\hline & +0.25 & -49.101 & +5.575 & +1.879 \\
\hline & +0.5 & -96.86 & +11.152 & +2.1745 \\
\hline
\end{tabular}

Table 2. Effects of parameter changes on optimal values of the second scenario.

\begin{tabular}{|c|c|c|c|c|}
\hline \multicolumn{5}{|c|}{ Changes in parameter's values } \\
\hline & Changes in parameter & $T$ & $p$ & $T P$ \\
\hline \multirow{4}{*}{$h$} & -0.5 & +16.711 & -5.45 & +5.679 \\
\hline & -0.25 & +8.755 & -2.639 & +3.175 \\
\hline & +0.25 & -9.173 & +2.4116 & -3.604 \\
\hline & +0.5 & -18.064 & +4.528 & -7.322 \\
\hline \multirow{4}{*}{$\theta$} & -0.5 & -0.356 & +0.001 & -0.002 \\
\hline & -0.25 & -0.172 & -0.0002 & +0.0003 \\
\hline & +0.25 & +0.184 & -0.001 & +0.002 \\
\hline & +0.5 & +0.368 & -0.002 & +0.003 \\
\hline \multirow{4}{*}{$C_{H}$} & -0.5 & +0.368 & -0.002 & +0.003 \\
\hline & -0.25 & +0.184 & -0.001 & +0.002 \\
\hline & +0.25 & -0.172 & -0.0002 & +0.0003 \\
\hline & +0.5 & -0.356 & +0.001 & -0.002 \\
\hline \multirow{4}{*}{$C^{\prime}$} & -0.5 & -32.870 & -7.343 & +6.840 \\
\hline & -0.25 & -14.96 & -4.066 & +4.557 \\
\hline & +0.25 & +11.85 & +4.770 & -7.78 \\
\hline & +0.5 & +20.67 & +10.133 & -19.66 \\
\hline
\end{tabular}

$20, b=0.3, a=10, C_{D}=3, C_{p}=30, T^{\prime}=1.5, \delta=35$, and $C_{R}=40$. According to the above-mentioned solution procedure, the highest profit obtains $T P=$ 111.1546 which corresponds to the optimum value of $p^{*}=37.7664$ as retailer's selling price and optimum value of $T^{*}=0.8132$ as order cycle length.

\section{Sensitivity analysis}

In this part, we have conducted several numerical experiments to investigate the sensitivity of optimal solutions to changes in parameter's values, and the results are shown in Tables 1 and 2 and Figures 4 to 7 . Also, it must be said that in both figures and tables, the percent of changes in decision variables with respect to percentage of parameter's values changes is shown. In this part, the sensitivity analysis is only conducted on the most effective parameters such as $C_{H}, C^{\prime}, h$, and $\theta$.

Figure 4 represent the effects of change in holding cost $(h)$ on optimal values of retailer's selling price and order cycle length in both scenarios (with and without shortage). And, as is seen that there is a direct relationship between changes in holding cost and changes in optimal values of retailer's selling price and 

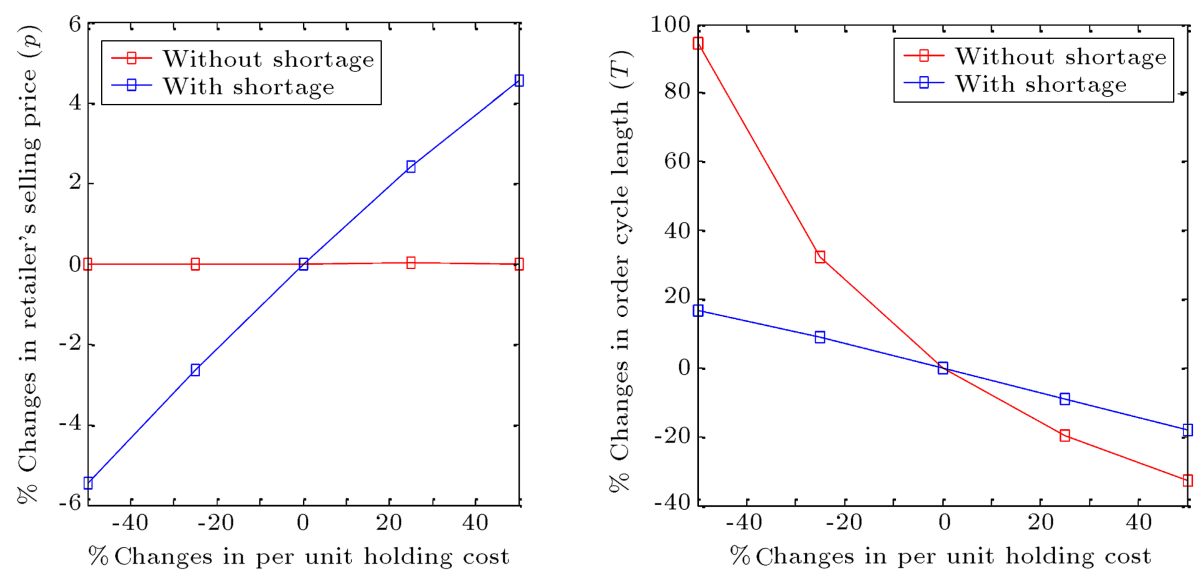

Figure 4. Effects of changes in holding cost on decision variables.
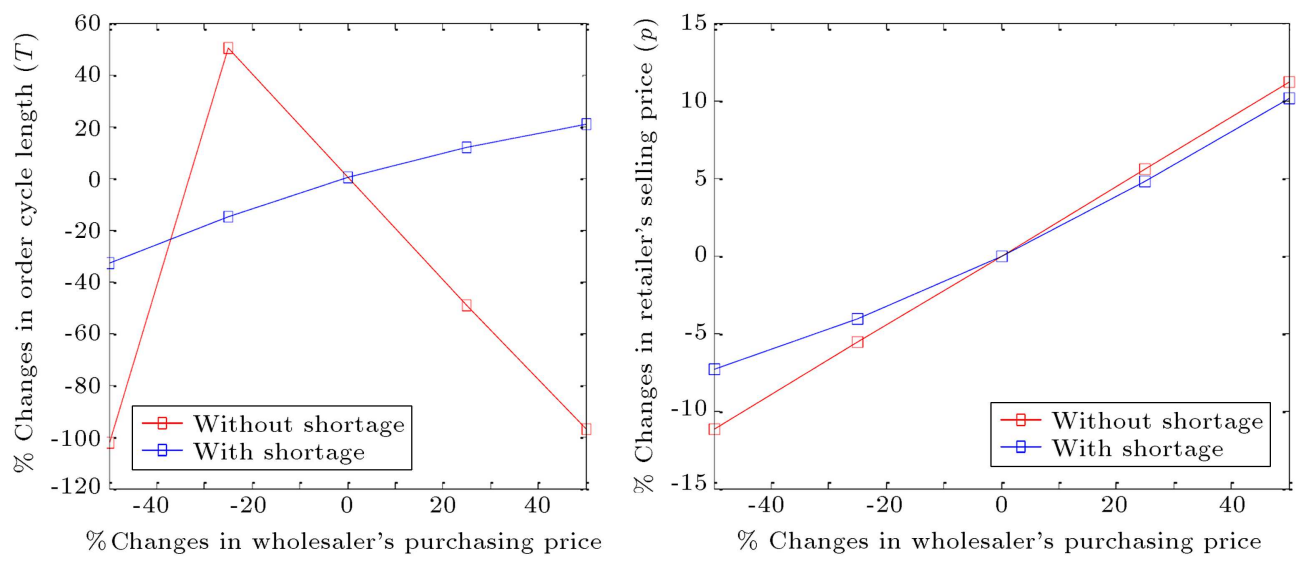

Figure 5. Effects of changes in wholesaler's purchasing price on decision variables.
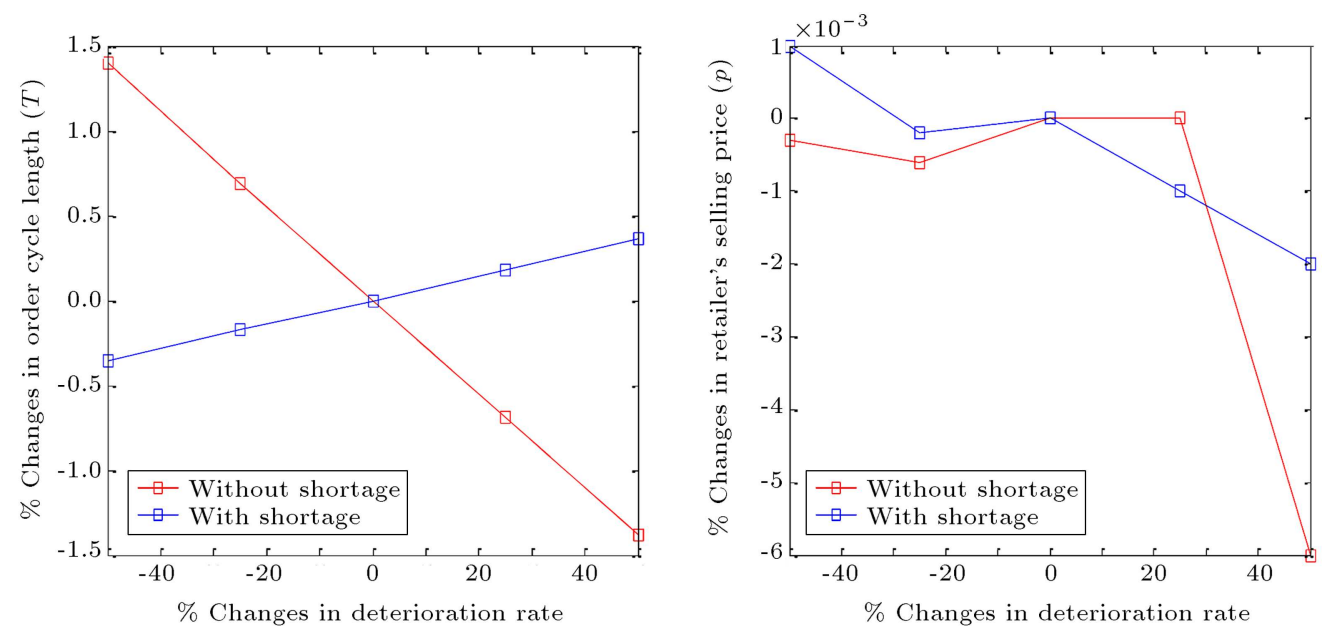

Figure 6. Effects of changes in deterioration rates on decision variables.

a reverse relationship between changes in holding cost and changes in optimal values of order cycle length. The optimal values of retailer's selling price increase as per unit holding cost increases and the optimal values of order cycle length decrease as the per unit holding cost increases.

Figure 5 represents the effects of changes in wholesaler's purchasing price $\left(C^{\prime}\right)$ on optimal values of retailer's selling price and order cycle length in both scenarios (with and without shortage). And, as is seen, there is a direct relationship between changes in wholesaler's purchasing price and changes in optimal value of retailer's selling price (in both scenarios) and order cycle length (in the scenario with shortage). The optimal values of retailer's selling price (in both scenarios) and order cycle length (in the scenario with shortage) 

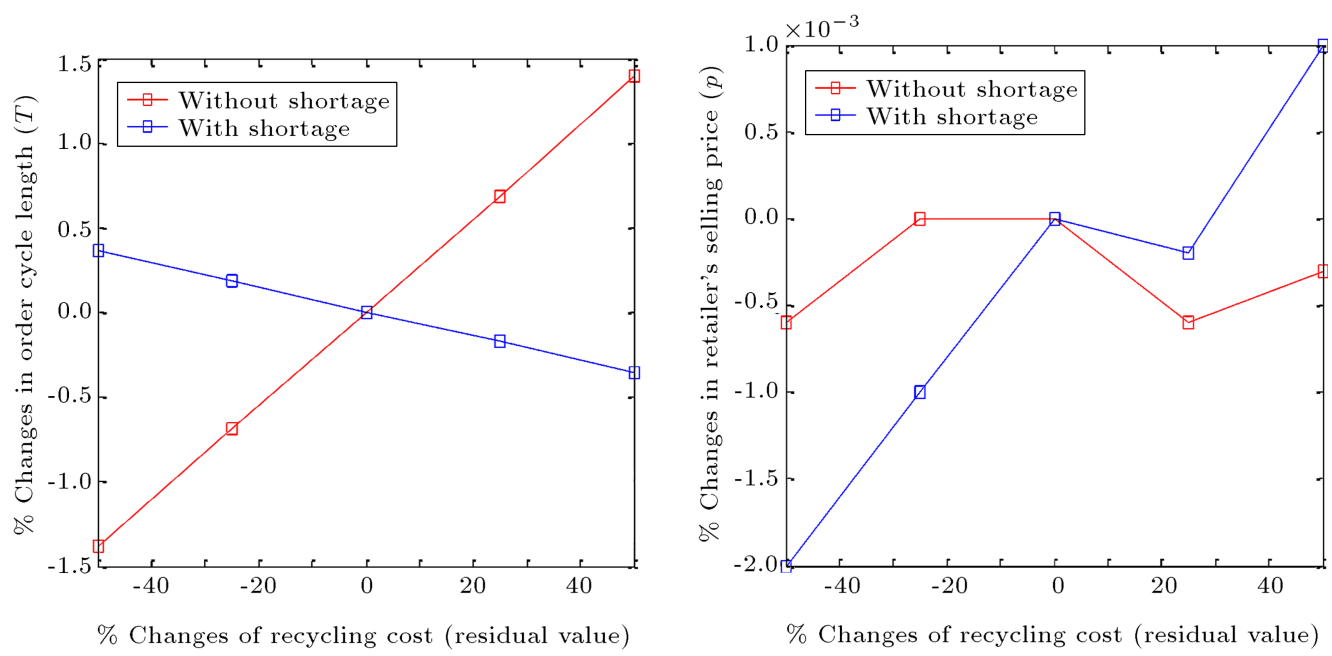

Figure 7. Effects of changes in recycling cost (residual value) on decision variables.

increase as the wholesaler's purchasing price increases. But, the optimal value of order cycle length (in the scenario without shortage) first increases, and then decreases as the wholesaler's purchasing price increases.

Figure 6 represents the effects of changes in deterioration rate $(\theta)$ on optimal values of retailer's selling price and order cycle length in both scenarios (with and without shortage). And, as is seen, there is an alternative and also a reverse relationship between changes in deterioration rate and changes in retailer's selling price (in both scenarios), a reverse relationship between changes in deterioration rate and changes in order cycle length (in the scenario without shortage), and finally, a direct relationship between changes in deterioration rate and changes in order cycle length (in the scenario with shortage).

Figure 7 represents the effects of change in recycling cost $\left(C_{H}\right)$ on optimal values of retailer's selling price and order cycle length in both scenarios (with and without shortage). And, as is seen, there is an alternative and also a direct relationship between changes in recycling cost and changes in optimal values of retailer's selling price (in both scenarios), a reverse relationship between changes in recycling cost and changes in order cycle length (in the scenario with shortage), and finally, a direct relationship between changes in recycling cost and changes in order cycle length (in the scenario without shortage).

\section{Conclusion}

In this paper, a two-stage supply chain with a single deteriorating product system is considered, and two mathematical models for jointly determining the optimum values of retailer's selling price $p$ and order cycle length $T$ under two different scenarios (with and without shortage assumption) are presented. Also, in this study, since products are deteriorating, a re- placement cost for deteriorating items is considered, in which the deteriorated products are recycled and healthy products are replaced instead. Then, using some theorems, the concavity of profit functions of the two proposed models is proved. Finally, a solution method (algorithm) is proposed to solve the models. At the end, numerical examples are provided to show the applicability of the proposed policies. The presented models in this paper are comprehensive and considered nearly all costs of an inventory system. For the future studies, permissible delay in payments, promotions, and stochastic and fuzzy demands can be considered.

\section{References}

1. Yu, Y., Wang, Z. and Liang, L. "A vendor managed inventory supply chain with deteriorating raw materials and products", International Journal of Production Economics, 136(2), pp. 266-274 (2012)

2. Huang, Y., Huang, G.Q. and Newman, S.T. " Coordinating pricing and inventory decisions in a multi-level supply chain: A game theoric approach", Transportation Research Part E, 47, pp. 115-129 (2011).

3. Ghoreishi, M., Mirzazadeh, A. and Kamalabadi, I.N. "Optimal pricing and lot-sizing policies for an economic production quantity model with noninstantaneous deteriorating items, permissible delay in payments, customer returns, and inflation", Proceedings of the Institution of Mechanical Engineers, Part B: Journal of Engineering Manufacture, 228(12), pp. 1653-1663 (2014).

4. Zhu, S.X. "Joint pricing and inventory replenishment decisions with returns and expediting", European Journal of Operation Research, 216, pp. 105-112 (2012).

5. You, P.S., Ikuta, S. and Hsieh, Y.C. "Opimal ordering and pricing policy for an inventory system with trial periods", Applied Mathematical Modeling, 34, pp. 3179-3188 (2010). 
6. Lee, C.-T., Chiu, H.-N. Yeh, R.H. and Huang, D.-K. "Application of a fuzzy multilevel multi objective production planning model in a network product manufacturing supply chain", Proceedings of the Institution of Mechanical Engineers, Part B: Journal of Engineering Manufacture, 226(12), pp. 2064-2074 (2012).

7. Su, Y. and Geunes, J. "Price promotions, operations cost, and profit in a two-stage supply chain", Omega, 40, pp. 891-905 (2012).

8. Mutlu, F. and Çetinkaya, S. "Pricing decisions in a carrier-retailer channel under price-sensitive demand and contract-carriage with common-carriage option", Transportation Research Part E: Logistics and Transportation Review, 51, pp. 28-40 (2013).

9. Hong, K.-S. and Lee, C. "Optimal time-based consolidation policy with price sensitive demand", International Journal of Production Economics, 143(2), pp. 275-284 (2013).

10. Abad, P.L. "Optimal price and order size under partial backordering incorporating shortage, backorder and lost sale costs", International Journal of Production Economics, 114, pp. 179-186 (2008).

11. Adida, E. and Perakis, G. "A nonlinear continuous time optimal control model of dynamic pricing and inventory control with no backorders", Naval Research Logistics, 54, pp. 767-795 (2007).

12. Dong, M., Yang, D., Wang, C. and Shao, X. "Product line selection and pricing under modular composition choices and inventory pooling strategy", Proceedings of the Institution of Mechanical Engineers, Part B: Journal of Engineering Manufacture, 225(4), pp. 587598 (2011).

13. Gümüs, A.T. and Güneri, A.F. "Multi-echelon inventory management in supply chains with uncertain demand and lead times: literature review from an operational research perspective", Proceedings of the Institution of Mechanical Engineers, Part B: Journal of Engineering Manufacture, 221(10), pp. 1553-1570 (2007).

14. Chew, E.P., Lee, C. and Liu, R. "Joint inventory allocation and pricing decisions for perishable products", International Journal of Production Economics, 120, pp. 139-150 (2009).

15. Taleizadeh, A. and Nematollahi, M. "An inventory control problem for deteriorating items with backordering and financial considerations", Applied Mathematical Modelling, 38.1, pp. 93-109 (2014).

16. Lee, C.F. and Chung, C.P. "An inventory model for deteriorating items in a supply chain with system dynamics analysis", Procedia-Social and Behavioral Sciences, 40, pp. 41-51 (2012).

17. Maity, K. and Maiti, M. "A numerical approach to a multi-objective optimal inventory control problem for deteriorating multi-items under fuzzy inflation and discounting", Computer and Mathematics with Applications, 55, pp. 1794-1807 (2008).
18. Yu, Y., Wang, Z. and Liang, L. "A vendor managed inventory supply chain with deteriorating raw materials and products", International Journal of Production Economics, 136, pp. 266-274 (2012).

19. Mahata, G.C. "An EPQ-based inventory model for exponentially deteriorating items under retailer partial trade credit policy in supply chain", Expert Systems with Application, 39, pp. 3537-3550 (2012).

20. Chung, K.-J., Chu, P. and Lan, S.-P. "A note on EOQ models for deteriorating items under stock-dependent selling rate", European Journal Of Operation Research, 124, pp. 550-559 (2000).

21. Yang, P.C. "Pricing strategy for deteriorating items using quantity discount when demand is price sensitive", European Journal of Operational Res earch, 157, pp. 389-397 (2004).

22. Dye, C.Y., Ouyang, L.Y. and Hsieh, T.P. "Inventory and pricing strategies for deteriorating items with shortages: A discounted cash flow approach", Computers \& Industrial Engineering, 52.1, pp. 29-40 (2007).

23. Tsao, Y.C. and Sheen, G.J. "Dynamic pricing, promotion and replenishment policies for a deteriorating item under permissible delay in payments", Computers \& Operations Research, 35.11, pp. 3562-3580 (2008).

24. Huang, C.K. "An integrated inventory model under conditions of order processing cost reduction and permissible delay in payments", Applied Mathematical Modeling, 34, pp. 1352-1359 (2010).

25. Maihami, R., Nakhai, I. "Joint control of inventory and its pricing for non-instantaneously deteriorating items under permissible delay in payments and partial backlogging", Mathematical and Computer Modeling, 55, pp. 1722-1733 (2012).

26. Rivera-Gomes, H., Gharbi, A. and Kenne, J.P. "Joint production and major maintenance planning policy of a manufacturing system with deteriorating quality", International Journal of Production Economics, 146, pp. 575-587 (2013).

27. Khanh Nguyen, T.P., Yeung, Th.G. and Castanier, B. "Optimal maintenance and replacement decisions under technological change with consideration of spare parts inventories", International Journal Of Production Economics, 143, pp. $472-477$ (2013).

28. Jain, M. and Gupta, R. "Optimal replacement policy for a repairable system with multiple vacations and imperfect fault coverage", Computers \& Industrial Engineering, 66, pp. 710-719 (2013).

29. Berthaut, F., Gharib, A., Kenné, J.P. and Boulet, J.F. "Improved joint preventive maintenance and hedging point policy", International Journal of Production Economics, 127(1), pp. 60-72 (2010).

30. Guchhait, P., Maiti, M.K. and Maiti, M. "Imperfect production policy of a breakable item with variable breakability and demand in random planning horizon", International Journal of Mathematics in Operational Research, 4(6), pp. 622-637 (2012). 
31. Cheng, G.Q. and Li, L. "An optimal replacement policy for a degenerative system with two-types of failure states", Journal Of Computational and Applied Mathematics, 261, pp. 139-145 (2014).

32. Chang, C.C. "Optimum preventive maintenance policies for systems subject to random working times, replacement, and minimal repair", Computer \& Industrial Engineering, 67, pp. 185-194 (2014).

33. Sivazlian, B.D. and Danusaputro, S.L. "Economic inventory and replacement management of a system in which components are subject to failure", Microelectronics Reliability, 29, pp. 861-881 (1989).

34. Teimoury, E. and Fathi, M. "A queueing-game model for making decisions about order penetration point in supply chain in competitive environment", International Journal of Strategic Decision Sciences (IJSDS), 4(4), pp. 1-24 (2013).

35. Teimoury, E., Fathian, M. and Chambar, I. "Automation of the supply chain performance measurement based on multi-agent system", International Journal of Agile Systems and Management, 6(1), pp. 25-42 (2013).

36. Teimoury, E. and Fathi, M. "An integrated operationsmarketing perspective for making decisions about order penetration point in multi-product supply chain: a queuing approach", International Journal of Production Research, 51(18), pp. 5576-5596 (2013).

37. Teimoury, E. and Haddad, H. "A supply chain production scheduling with deterioration and release date", International Journal of Rapid Manufacturing, 3(4), pp. 195-208 (2013).
38. Taleizadeh, A.A., Noori-Daryan, M. and CárdenasBarrón, L.E. "Joint optimization of price, replenishment frequency, replenishment cycle and production rate in vendor managed inventory system with deteriorating items", International Journal of Production Economics, 159, pp. 285-295 (2015).

39. Rahdar, M. and Nookabadi, A. "Coordination mechanism for a deteriorating item in a two-level supply chain system", Applied Mathematical Modelling, 38, pp. 2884-2900 (2014).

40. Sarkar, B. "A production-inventory model with probabilistic deterioration in two-echelon supply chain management", Applied Mathematical Modelling, 37, pp. 3138-3151 (2013).

\section{Biographies}

Ebrahim Teimoury is an Associate Professor of University of Science and Technology (Iran). He graduated from Amirkabir University of Technology in 1990 and was awarded an MSc and a PhD degrees from University of Science and Technology, respectively. he has published many papers in international journals. Most of his research papers have been cited in many articles.

Seyed Mohammad Mehdi Kazemi is currently a PhD Candidate in University of Science and Technology since 2011. He graduated from University of Science and Technology and was awarded an MSc degree from Amirkabir University of Technology. Also, he has inventions which have patents. 